\title{
Fish flourish on anxiety drug
}

Pharmaceutical pollutants in water seem to benefit at least one species - effects that could be missed by standard risk assessments.

\section{Simon Makin}

08 August 2014

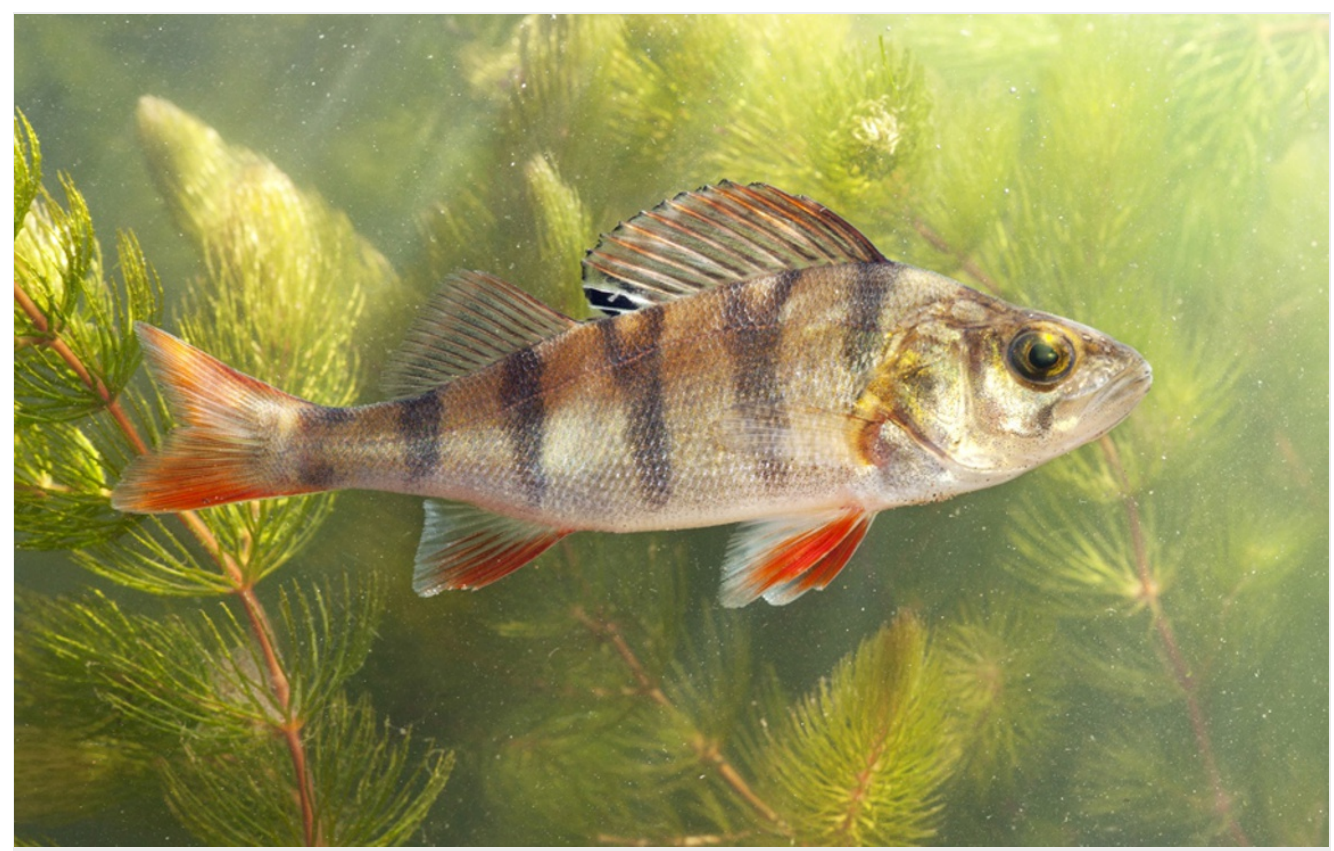

Jelger Herder/Buiten-beeld/Getty

Studies of the impact of pharmaceuticals on fish such as the English perch may have overlooked positive effects, researchers claim.

Fish that have been exposed to a common anti-anxiety drug are more active and have better chances of survival than unexposed fish, researchers report in Environmental Research Letters ${ }^{1}$. The results suggest that standard methods for assessing the environmental impact of pharmaceuticals in waterways might miss some of the drugs' effects because they focus exclusively on harms, according to the authors.

In the study, researchers led by Jonatan Klaminder at Umeå University in Sweden exposed Eurasian perch (Perca fluviatilis) to oxazepam, one of a widely used class of anti-anxiety drugs called benzodiazepines.

Standard ecotoxicology experiments use unstressed, healthy fish that have been bred in labs. Control groups are designed to have $100 \%$ survival rates so that decreases in survival in the test group are easy to detect by comparison. But it is difficult to detect any increase in survival rates when the control group already has nearly complete survival.

So Klaminder and his colleagues used the opposite approach. They exposed fish to the drug at two sensitive life stages: two-year-old wild fish taken from a Swedish lake that had only recently thawed after winter, and strings of roes — fish eggs that contain embryos undergoing development. These are more realistic conditions, the researchers say, as animals in the wild often experience high mortality.

The researchers used oxazepam at a high concentration of 1,000 micrograms per litre and at a low concentration of $1 \mu \mathrm{g} \mathrm{I} \mathrm{I}^{-1}$. The low dose is relevant to aquatic environments in urban areas, because oxazepam concentrations of $1.9 \mu \mathrm{g} \mathrm{I}^{-1}$ have been measured in effluents from wastewater treatment plants.

Mortality was high in the untreated groups of fish and hatchlings, as in the wild. But the higher drug concentration improved survival in hatchlings compared with the unexposed and low-concentration groups, and both doses improved survival in the mature fish. "It's a new era of contamination research if we want to include pharmaceuticals, because their effects are not as traditional as our thinking," 
says Klaminder.

\section{Wider web effects}

Still, such effects are not necessarily good for ecosystems as a whole. "If a pharmaceutical has a beneficial effect on one species, this is likely to have negative effects on prey or competitor species," says Kathryn Arnold, an ecologist at the University of York, UK. "Current risk assessment doesn't take into account these indirect effects via the food web."

Last year, Klaminder's team showed that oxazepam changes the behaviour of fish ${ }^{2}$ (see "Anti-anxiety drug found in rivers makes fish more aggressive"). Similar effects were seen in the latest study. Exposed fish were more active, bolder and less sociable. It was while studying these behavioural effects that the team noticed the effect on survival, says Klaminder.

Although increased activity might seem a surprising response to a drug that relaxes people, the researchers believe that it could be caused by reduced stress, which in turn makes the fish bolder. The fish thus spend less time with their pals and more time foraging for food, which might explain their improved survival rate.

But Klaminder cautions that it is impossible to say whether these behavioural changes would have the same effect on survival in the wild, where they could even be harmful. "A small fish that becomes bolder and leaves its friends is likely to end up in the stomach of a predator," he says.

Another possible explanation is the phenomenon of hormesis, in which low concentrations of a drug can have an opposite effect to higher concentrations, says Alistair Boxall, an environmental scientist also at the University of York. Unfortunately, nobody really understands how hormesis works. Still, he adds, "It's an interesting angle on it."

A bigger question might be whether the effect extends to other drugs, species and sets of conditions. "It's definitely something that should be followed up," says Gerald Ankley, a research toxicologist at the US Environmental Protection Agency in Duluth, Minnesota. "But based on this one set of conditions, it would be premature to talk about changing how testing is done, without additional work."

Nature I doi:10.1038/nature.2014.15694

\section{References}

1. Klaminder, J., Jonsson, M., Fick, J., Sundelin, A. \& Brodin, T. Environ. Res. Lett. 9, 084003 (2014).

2. Brodin, T., Fick, J., Jonsson, M. \& Klaminder, J. Science 339, 814-815 (2013). 